\title{
MEMORIA VERSUS OLVIDO: LA PARADOJA DE INTERNET ${ }^{1}$
}

\author{
Forget vs. Memory: The Internet paradox
}

Teresa Ayala Pérez*

\begin{abstract}
RESUMEN
Desde que se produjo la masificación de la tecnología digital en la década de 1990, todo el entorno social, comunicativo y cultural se vio modificado, pero quizá uno de los aspectos más oscuros de esta nueva realidad es la cantidad de datos - personales, financieros, políticos o institucionales- que circulan por el ciberespacio, muchos de los cuales no pueden ser borrados. El concepto de memoria parece adquirir nuevos significados en la era digital, debido a lo cual en el presente trabajo se intenta reflexionar respecto del ciberespacio, la memoria y la escasa posibilidad del olvido digital, por lo que se plantea un nuevo derecho, el llamado the right to be forgotten: el derecho a ser olvidado.
\end{abstract}

Palabras clave: memoria, ciberespacio, derecho a ser olvidado, Web.

\begin{abstract}
Since massification of digital technology occurred in 1990s, all social, communicative and cultural environment was changed, but perhaps one of the darkest aspects of this

${ }^{1}$ Este trabajo se origina en el Proyecto Conicyt / Fondecyt No 1130294 "Uso de la Web, competencias, motivación y actitud de los estudiantes de pedagogía del área de humanidades respecto de las TIC y la cultura digital”. Fue expuesto, en parte, en el XVII Congreso Internacional de Humanidades en 2014.

* Facultad de Historia, Geografía y Letras. Departamento de Castellano. Universidad Metropolitana de Ciencias de la Educación. Santiago, Chile. Correo electrónico: teresa.ayala@umce.cl

Artículo recibido el 13 de marzo de 2015. Aceptado el 24 de octubre de 2015.
\end{abstract}


new reality is the amount of personal, financial, political or institutional data circulating in cyberspace, many of which can not be erased. The concept of memory it seem to acquire new meanings in the digital age, so in this paper attempts to reflect on cyberspace, memory and the low chance of digital oblivion, so that a new law raises, called the right to be forgotten.

Keywords: memory, cyberspace, the right to be forgotten, Web.

\section{INTRODUCCIÓN}

De acuerdo con Salarelli (2014), por cientos de años se ha debatido respecto de cómo el cerebro humano es capaz de retener y organizar los recuerdos. Lo que han demostrado los estudios más recientes es que la memoria humana no funciona sobre la base de esquemas clasificatorios estables e inmutables: la memoria humana se reescribe continuamente sobre la base de los estímulos a los que está sometido el sujeto durante su existencia, no solo fortaleciendo los lazos mutuos entre los recuerdos, sino también eliminando lo que ya no es útil a las necesidades del momento. Sin embargo, desde que se produjo la masificación de la tecnología digital en la década de 1990, todo el entorno social, comunicativo y cultural se vio modificado y quizá uno de los aspectos más oscuros de esta nueva realidad es la cantidad de datos - personales, financieros, políticos o institucionales- que circulan por el ciberespacio, muchos de los cuales no pueden ser borrados, por lo cual esta posibilidad de eliminar lo que ya no es útil no funciona como se supone que naturalmente ocurre en el cerebro humano. Al hablar de memoria, este concepto parece adquirir nuevos significados en la era digital, por lo que en el presente trabajo se intenta reflexionar respecto del ciberespacio, la memoria y la escasa posibilidad del olvido digital, el llamado "derecho a ser olvidado".

El presente trabajo nace como una reflexión que surgió a partir de entrevistas y grupos focales que se desarrollaron como parte del proyecto "Uso de la Web, competencias, motivación y actitud de los estudiantes de pedagogía del área de humanidades respecto de las TIC y la cultura digital" en la medida de que los jóvenes, a pesar de que afirman que se entrega mucha información personal a través de la Red en general y de las redes sociales en particular, están conscientes de los peligros que implica no poder borrar datos que han sido subidos a Internet y que dicha información está siendo compartida con muchos usuarios, incluso desconocidos. Al mismo tiempo, en 2013 comenzaron a aparecer una serie de noticias en relación con la posibilidad de borrar la información personal en la Web o bien de no ser incluido en los buscadores, por lo cual se consideró pertinente reflexionar al respecto, especialmente porque el proyecto se centra en el ámbito de 
las humanidades, es decir, de la cultura inmaterial, aquella que se mantiene gracias a la memoria, al almacenamiento y preservación de ideofacturas, lo cual pareciera mostrar una paradoja: Internet es, sin duda, el más grande repositorio cultural que ha conocido el hombre, sin embargo, esta capacidad casi ilimitada restringe y amenaza un derecho fundamental del ser humano: el derecho de ser olvidado.

\section{LUGARES DE LA MEMORIA}

Para Eco (2003), tenemos tres tipos de memoria: la primera es orgánica, la de carne y sangre que administra nuestro cerebro; la segunda es mineral, la que la humanidad ha conocido bajo dos formas: hace miles de años en las tabletas de arcilla y los obeliscos y, en la actualidad, en la memoria electrónica, la de las computadoras hechas de silicio. Un tercer tipo de memoria, en tanto, es vegetal, representada por los primeros papiros y después por los libros, hechos de papel.

Durante siglos, el hombre ha intentado preservar sus mensajes a través de símbolos, en tiempos remotos, luego mediante la escritura y, en la actualidad, de la tecnología digital. La información debe ser transmitida de generación en generación y propagarse geográficamente para que la cultura y la sociedad se mantengan de acuerdo con el modelo que cada comunidad ha creado. Quizá con esta motivación y con el transcurso del tiempo, aparece el museo 'el templo de las musas', es decir, de las diosas de la memoria, y tanto en Grecia como en Roma se establecieron recintos en donde se guardaban objetos que para sus dueños eran dignos de ser atesorados y exhibidos, por ejemplo, para recordar triunfos o para demostrar su riqueza y poderío. Sin embargo, es en el Renacimiento en Florencia cuando se dan las condiciones para que la fértil producción artística sea guardada y mostrada al público, por lo cual muchos consideran que la Galeria degli Uffizi -cuya construcción finaliza en 1580 - da inicio a lo que hoy conocemos como museo. Esta galería fue fundada gracias al apoyo de los Medici y abierta al público en 1765. En 1683 se crea el primer museo en Gran Bretańa, específicamente en Oxford, y un siglo más tarde se inauguran el Museo Británico (1759) en Londres y el Museo del Louvre en París (1793). El museo es, para la Real Academia Espańola, un 'lugar en que se guardan colecciones de objetos artísticos, científicos o de otro tipo, y en general de valor cultural, convenientemente colocados para que sean

examinados', como asimismo 'Institución, sin fines de lucro, abierta al público, cuya finalidad consiste en la adquisición, conservación, estudio y exposición de los objetos que mejor ilustran las actividades del hombre, o culturalmente importantes para el desarrollo de los conocimientos humanos'.

Pero así como el museo se convierte en el lugar donde se atesora la memoria material de los pueblos, la biblioteca conserva parte de la memoria inmaterial en 
libros que mantienen, muchas veces congelados en el tiempo, tradiciones, leyendas, historia, religión, literatura o filosofía. La biblioteca, del lat. bibliothèca, y este

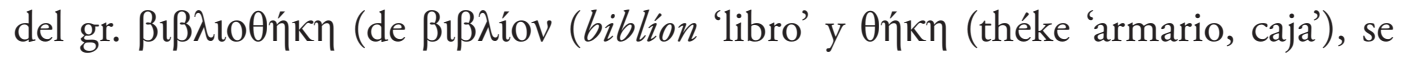
constituye en el lugar donde se almacenan y ordenan documentos con el propósito de que sean usados. Para la Real Academia Española, se trata de una 'Institución cuya finalidad consiste en la adquisición, conservación, estudio y exposición de libros y documentos'. En su sentido lingüístico más estricto, entonces, el museo y la biblioteca son lugares donde se comparten el saber y la cultura, donde se almacena aquello creado o lo que es importante para el hombre, puesto que si bien lo que no es importante se desecha, lo relevante se intenta preservar. Umberto Eco, en el llamado Discurso alejandrino (2003) afirma que:

Durante siglos, las bibliotecas fueron la manera más importante de guardar nuestra sabiduría colectiva. Fueron y siguen siendo una especie de cerebro universal donde podemos recuperar lo que hemos olvidado y lo que todavía no conocemos. Si me permiten la metáfora, una biblioteca es la mejor imitación posible de una mente divina, en la que todo el universo se ve y se comprende al mismo tiempo [Eco, 2003, en línea].

Pero el ser humano no solo busca conservar los productos culturales, sino también a su propia especie. La mayoría de los pueblos trata de preservar a sus muertos a través de distintas estrategias, desde la momificación hasta la creación de santuarios -construidos para recordar y honrar a los difuntos- o cementerios, entendidos estos como lugares sagrados e inviolables por lo que la profanación tanto del lugar como de los cuerpos es considerado una de las acciones más viles cometidas por el hombre. Además de estos lugares es posible mencionar los memoriales, lugares donde no se encuentran los fallecidos, pero sí su nombre con el mismo fin que los casos anteriores: recordar y honrar a quienes dejaron de existir. Junto con lo anterior, y desde tiempos remotos, una forma de mantener viva la memoria de los muertos es a través de estatuas o pinturas, e incluso a través de elementos simbólicos que los representen. En el caso de Latinoamérica, y de Chile en particular, la tradición de las animitas, es decir, 'pequeńa construcción que se erige en el lugar donde han muerto, por lo común de forma trágica, una o más personas, a las que se suele rendir homenaje encendiendo velas'. De acuerdo con el Diccionario de uso del español de Chile (2010) se ha mantenido tanto en las bermas de caminos y carreteras, como también en calles y avenidas de las grandes ciudades, probando así que ni siquiera con el avance trepidante del desarrollo urbano o vial esta práctica sigue viva. 


\section{LA REVOLUCIÓN DIGITAL}

Sin embargo, durante los años 70 comienza a gestarse una de las mayores revoluciones culturales de la historia de la humanidad: la masificación de las computadoras personales, gracias a los adelantos tecnológicos creados por IBM (International Business Machines), Apple Computers y Microsoft. Pero es a inicios de los años 90 cuando realmente comienza la era digital gracias a la creación de la World Wide Web por parte de Tim Berners-Lee, puesto que si bien Internet ya existía en los años 60 -como parte del proyecto ARPANET (Advanced Research Projects Agency Network) y Vinton Cerf ya había creado el Protocolo de Internet (IP) y el Protocolo de Transmisión ${ }^{2}$ (TCP) - la Web permite que cualquier persona que disponga de un computador y una conexión a Internet pueda ser un activo usuario de esta tecnología; ya no se trata solo de un proyecto secreto de Ministerio de Defensa de los Estados Unidos, sino de un cambio cultural mundial donde se utiliza lo que podría denominarse un lenguaje universal, el Hyper Text Markup Language ('Lenguaje de marcas de hipertexto') que se basa en los conceptos de hipertexto e hipervinculos propuestos por Theodor Holmes Nelson en 1965.

La Web es, en definitiva, una gran colección de documentos, una biblioteca virtual y el mayor repositorio cultural que ha conocido la humanidad. La cantidad de información que se almacena y circula en este espacio electrónico ni siquiera puede ser calculable y es el lugar de la memoria más grande creada por el hombre. Esta es la esencia de la Web: ser la memoria externa de la humanidad, la suma de infinitas memorias individuales y colectivas, a tal punto que Derrick de Kerckhove (1997) habla de las inteligencias en conexión. Así, propone comprender la cibercultura desde tres grandes características: la interactividad, es decir, "el enlace físico de la gente o de las industrias basadas en la comunicación (las industrias del cuerpo)", la hipertextualidad, es decir, "el enlace de contenidos o industrias basadas en el conocimiento (las industrias de la memoria)" y la conectividad, "o Webness ${ }^{3}$, el enlace mental de la gente o de las industrias de redes (las industrias de la inteligencia)" (De Kerckhove, 1999: 21). El resultado de las tres características descritas promueven lo que él denomina las inteligencias en conexión y afirma que "El

\footnotetext{
${ }^{2}$ Tecnología desarrollada por Vinton Cerf en 1973.

${ }^{3}$ Webness es un término acuñado por los jurados de arte de la categoría Web en el concurso Ars Electronica Prize de 1995. Para Kerckhove, "la propiedad de la Webness reside en la interconexión de inteligencias humanas mediante interfaces conectadas, con el propósito de innovar y descubrir. Es la convergencia de hipertexto, multimedia, realidad virtual, redes neuronales y vida artificial que configuran una nueva condición cognitiva denominada Webness, es decir, la esencia de toda red". Detrás de esta convergencia, Kerckhove percibe la digitalización de todos los contenidos, la interconexión de todas las redes, la humanización del software y del hardware de interfaz y los efectos globalizadores de los satélites.
} 
incremento en las interacciones humanas -personales, sociales e institucionales-, a través de las redes integradas, está concentrando y multiplicando la energía mental humana" (De Kerckhove, 1999: 175).

Por otra parte, el acceso a la información solo era posible en las bibliotecas -desde la mítica alejandrina, los conventos medievales hasta los venerables edificios neoclásicos, los con rasgos heredados de la Ilustración- donde se encontraba un número limitado de textos, muchos de ellos restringidos solo a una élite. Esta situación cambió con el advenimiento de la Web y desde los años 90 es posible acceder a un número prácticamente ilimitado de documentos desde cualquier lugar donde haya conexión a Internet. Es decir, la Web abrió múltiples posibilidades para acceder al conocimiento y en ella no solo hay lugar para los nuevos productos culturales que se van creando, sino que también es posible conocer documentos invaluables de un pasado remoto gracias a la digitalización de materiales que nunca estuvieron al alcance del público en general. Gracias a la Web es posible recorrer virtualmente museos, revisar los catálogos de cualquier biblioteca, leer libros, diarios y revistas de épocas pretéritas, acceder a documentos de cualquier naturaleza. Desde esta perspectiva, las tres memorias de las que habla Eco se funden en una y esta situación modifica de manera profunda a todas las comunidades que participan del ciberespacio.

Para Mayans i Planells (2003), en el ciberespacio las lógicas basadas en lo físico no son válidas y es una dimensión más accesible económicamente que otros canales de difusión e información, lo cual hace posible que puedan ser millones sus 'habitantes'. Resulta pertinente destacar que este concepto es anterior a la creación de la Web, puesto que es mencionado por primera vez en 1984 por William Gibson en la novela de ficción Neuromancer y fue definido entonces como algo intermedio entre la realidad virtual e Internet, como un universo paralelo al real. Pierre Lévy, en tanto, define el ciberespacio como "el espacio de comunicación abierta por la interconexión mundial de los ordenadores y de las memorias informáticas" (Lévy, 2007: 70). Scolari (2008) afirma que el ciberespacio se concibe, desde los años 90, no solo como el lugar de las comunicaciones, "sino también un generador de discursos, un espacio enunciativo donde una variedad de intereses declaman sus orígenes, mitos y tendencias futuras" (Scolari, 2008: 137), en tanto que para el filósofo y psicoanalista Slavoj Žižek (1993) el impacto social que tiene el ciberespacio no deriva directamente de la tecnología, sino que depende de la red de relaciones sociales y "la materialidad misma del ciberespacio genera automáticamente la ilusión de un espacio abstracto, con un intercambio 'libre de fricción' en el cual se borra la particularidad de la posición social de los participantes" (Žižek, 2008: 153). Los aspectos positivos de la Web en particular y del ciberespacio en general resultan evidentes en términos de la preservación de la memoria, sin embargo, ¿qué ocurre cuando alguien no quiere ser parte de este inconmensurable repositorio? ¿qué sucede si alguien quiere ser olvidado en la Web? 


\section{LA MEMORIA DIGITAL}

El éxito de la WWW radica no solo en la capacidad de almacenar, sino en las posibilidades de comunicación que les otorga a las personas. En sus inicios, la única herramienta comunicativa en Internet fue el correo electrónico, creado en 1965, aunque es en 1971 cuando se comienza a usar el símbolo @. Posteriormente, los grupos, foros y, por supuesto, Messenger entre 1999 y 2013 fue la aplicación favorita de millones de usuarios, pues permitía la comunicación directa a través del chat. Pero la verdadera revolución en las comunicaciones la constituye la creación en 2004 de la red social Facebook, en tanto que en 2005 se crea YouTube, el principal sitio para compartir vídeos y, posteriormente, en 2006, Twitter, servicio de microblogging, que se ha convertido en una de las aplicaciones más utilizadas de la Web. De acuerdo con las estadísticas de Facebook en su sitio Newsroom ${ }^{4}$, en marzo de 2014 mensualmente 1.000 millones de usuarios activos usan los productos móviles de Facebook. Respecto de Twitter, las estadísticas ${ }^{5}$ de inicios de 2014 indican que el número total de usuarios activos registrados es de 645.750.000; el número promedio de tweets por día es de 58 millones; el 43\% de los usuarios de Twitter usan el teléfono para 'twittear' y que 9.100 tweets circulan cada segundo.

Las redes sociales y comunidades virtuales son un lugar de encuentro y de expresión para quienes las integran; sin embargo, se desdibuja la distinción entre lo privado y lo público, especialmente porque los propios usuarios exponen desde sus relaciones sentimentales hasta sus opiniones políticas. En la comunicación digital hay una pérdida de los espacios privados, y en la cibercultura las personas parecieran verse obligadas a comunicar todo a través de Facebook, Twitter, YouTube, Instagram o Flickr, sin importar las consecuencias que esta sobreexposición puede provocar. Personajes públicos se han visto en problemas por expresar opiniones a través de las redes sociales, sin considerar que al momento de utilizar estos medios, dejaron de ser privadas. Los más jóvenes no dudan en publicar todo tipo de fotos y vídeos a través de la Red, sin comprender que cualquier persona puede verlas, lo cual confirma que en la cibercultura se tiende al exhibicionismo y al deseo incontrolable de compartir sus vidas a través de Internet y convertirse, de alguna manera, en alguien "famoso". Como afirma Mark Dery (2010), aludiendo a Foucault respecto de la vigilancia y el castigo: "En la era de YouTube y Twitter, Facebook y Flickr, hemos aprendido a dejar de preocuparnos y amar al panóptico"” (nuestra traducción). Además, el uso

\footnotetext{
${ }^{4}$ Ver http://newsroom.fb.com/content/default.aspx?NewsAreaId=22.

${ }^{5}$ Fuente: Twitter, Huffington Post, eMarketer. Ver http://www.statisticbrain.com/twitter-statistics/

6 "In the age of YouTube and Twitter, Facebook and Flickr, we've learned to stop worrying and love the panopticon".
} 
de teléfonos celulares con cámaras incorporadas, permiten que las personas filmen o fotografíen todo tipo de situaciones tanto privadas como públicas para luego compartir estos registros a través de las redes sociales sin importar si con ello violan la privacidad o vulneren el honor o la reputación de las personas. Al respecto, antes de la aparición de la Web, McLuhan, 'el profeta de los medios', afirmaba lo siguiente:

¡El shock del reconocimiento! En un ambiente de información eléctrica, los grupos minoritarios ya no pueden ser contenidos -ignorados. Demasiadas personas saben demasiado las unas de las otras. Nuestro nuevo ambiente obliga al compromiso y a la participación. Cada uno de nosotros está ahora irrevocablemente envuelto en la vida de los demás, y es responsable de ellos (McLuhan y Fiore, 2009: 24).

A través de estas redes sociales circulan millones de datos e imágenes personales, pero el problema está en que muchos de ellos no se pueden borrar. De hecho, la política de Facebook hace prácticamente imposible "desaparecer" en la Web en la medida que no se pueden borrar los datos expuestos. Para Salarelli (2014), la consecuencia de esta nueva perspectiva es que estamos empantanados en una avalancha de información sobre nuestro pasado que puede limitar seriamente nuestra situación actual, impidiéndonos de actuar en plena libertad contra un futuro, cuyo diseño está fuertemente condicionado por las huellas que hemos dejado en nuestro pasado. Además, la cantidad de material recuperable a través de los sistemas de restauración de información más comunes, los motores de búsqueda, presenta tales niveles de fragmentación y descontextualización que la tendencia hacia apisonar la dimensión temporal, respetando el orden cronológico de producción de los documentos, así como la pérdida de la relación de autoridad entre el autor y el contenido son más que solo un riesgo temido, sino que son más bien un hecho. Por este motivo, agrega, la perspectiva de una memoria digital cada vez más amplia, estable e imperecedera debe, entonces, ser reconciliada con la presencia de factores de riesgo estructurales (envejecimiento de los soportes materiales y obsolescencia de los formatos de digitalización) y funcionales (la definición de herramientas eficaces de utilización de los datos) que representan las mismas causas de un posible olvido de la información en la era digital (nuestra traducción). El tráfico de datos en la Web puede ser entendida como un símbolo de la transparencia que exige la sociedad actual y, por el mismo motivo, hay muchas personas que se niegan a las posibles regulaciones que gobiernos o instituciones establezcan respecto del uso de la Red. Desde esta perspectiva, se enfrentan dos fuerzas: la libertad de expresión, por un lado, y el derecho a la privacidad, por otro. Así, en Estados Unidos se está iniciando el debate respecto del llamado "Online Privacy Rights" (Tich, 2013). 
Para Viktor Mayer Schomberger (2009), en la era digital recordar se ha convertido en la norma y olvidar en la excepción, pues la economía de almacenamiento ha hecho que olvidar sea brutalmente caro. Hasta hace poco tiempo el olvido era más fácil y barato que recordar, pero hoy el olvido requiere esfuerzo y gasto. Con la ayuda de las herramientas digitales -individualmente y como sociedad- hemos comenzado a "olvidar el olvido", como asegura Mayer Schomberger, pues hemos borrado de nuestras prácticas cotidianas uno de los mecanismos de comportamiento más fundamentales de la humanidad. Las implicaciones son inciertas, pero potencialmente preocupantes, puesto que un comentario en un periódico escolar puede dañar la futura carrera de un joven, o se podrá protestar contra una corporación que luego se negará a hacer negocios con nosotros.

En agosto de $2014^{7}$ Google defendió su decisión de revelar la identidad de un posible pedófilo residente en Houston, Texas, quien mantenía imágenes pornográficas en su cuenta de Gmail. Google, al igual que otros proveedores de Internet, utilizan algoritmos para revisar los correos electrónicos como parte de su estrategia de afinar anuncios de publicidad de acuerdo con los intereses del usuario. Así, la compañía escanea automáticamente las cuentas de Gmail, que tiene más de 400 millones de usuarios a nivel mundial. Sin embargo, el caso de Texas ha generado un debate sobre hasta dónde esta compañía monitorea las cuentas de los usuarios y provee información a otras instituciones. En abril de 2015, Google actualizó los términos y condiciones que deben aceptar los usuarios de su servicio de correo electrónico y el texto admite que la empresa analiza los correos de los usuarios para ofrecer tanto resultados de búsquedas más afinados como publicidad más ajustada a los intereses de los internautas. Dichos términos y condiciones señalan que: "Nuestros sistemas automatizados analizan su contenido (incluyendo emails) para ofrecer características relevantes y personalizadas de los productos como resultados adecuados a sus intereses, y detección de spam y malware. Este análisis ocurre cuando el contenido es enviado, recibido y cuando está almacenado" ${ }^{\text {. }}$

Los datos que los usuarios suben a Internet dejan de ser privados al momento que forman parte del ciberespacio, puesto que aunque se utilicen archivos encriptados o herramientas de seguridad, igualmente dichos mecanismos pueden ser violados no solo por hackers, tal como ocurrió con la compañía Sony

\footnotetext{
7 Ver http://www.latercera.com/noticia/mundo/bbc-mundo/2014/08/1433-589902-9-por-quegoogle-esta-revisando-los-correos-de-gmail.shtml.

${ }^{8}$ Ver http://www.bbc.co.uk/mundo/noticias/2014/08/140805_google_pornografia_gmail_am(5 de agosto de 2014).
} 
Pictures $^{9}$ y el disco de Madonna ${ }^{10}$ en 2014 , sino por cualquier persona un tanto más avezada que el promedio en materia informática. Pero, además, dichos datos deberían ser susceptibles de ser borrados de la Web cuando los usuarios lo estimen conveniente, independientemente de cuál sea la razón. Sin embargo, esto hasta el momento no ocurre, por lo que en enero de 2012 la Unión Europea propuso el "Derecho de ser olvidado" (the right to be forgotten). Este derecho, en términos generales, establece que los proveedores de los servicios de la Web deben eliminar los datos que los usuarios soliciten, como también incluir la opción de no poder ser buscado, es decir, el individuo debiera tener la opción de no ser "googleado" si así lo estima pertinente. El hecho que motivó que la justicia se pronunciara fue el reclamo de un hombre de negocios, quien fue detenido al ser sorprendido teniendo relaciones sexuales en un tren camino a Londres. El periódico Daily Mail publicó la noticia y, después de seis años del incidente, seguía apareciendo en el buscador, por lo que el individuo solicitó a Google ser borrado y lo consiguió. Posteriormente, un ciudadano español, que apareció como moroso cada vez que se buscaba en Internet, reclamó al buscador y cinco años después el Tribunal Europeo acogió su solicitud de ser eliminado del motor de búsqueda. En ambos casos se ejerció el Derecho al olvido en Internet que determina que cualquier persona pueda solicitar que Google -que acumula más del 80\% del mercado de búsquedas en Europa-olvide su nombre, razón por la cual ya se habían recibido cerca de 120.000 peticiones en 2014, aunque la fundación Wikimedia lucha por el derecho "al no olvido": dos webs recogen las noticias que están siendo eliminadas bajo la premisa de la libre información, debido a que criminales han solicitado ser desindexados.

En Latinoamérica, por su parte, no se observa una acción conjunta respecto de la protección de datos, sin embargo, en México existe la "Ley de Protección de Datos Personales en Posesión de Particulares" (2010); en Uruguay, en 2008 se promulgó la Ley $\mathrm{N}^{\circ} 18.331$ sobre "Protección de Datos Personales y Acción de Habeas Data”; en Colombia, la Ley 1581 "Ley Estatutaria de Protección de Datos Personales" fue promulgada en 2012 y se aplica desde 2013; en Argentina, el año 2002 fue creada la Dirección Nacional de Protección de Datos Personales, en tanto que la ley $\mathrm{N}^{\circ} 25.326$ es específica a dichos casos: "Ley de Protección de Datos Personales". En Perú, en 2011 se publicó la Ley 29733, "Ley de Protección de Datos Personales", mientras que en Nicaragua se aprobó la Ley 787 de "Protección de los Datos Personales". En Chile, la Ley 19.628 de 1999 también alude a la

\footnotetext{
${ }^{9}$ Cinco películas fueron filtradas en Internet. Se presume que hackers de Corea del Norte ingresaron al sitio de Sony con objeto de boicotear la película "The Interview", una sátira a dicho país y a su gobernante Kim Jong-Un.

${ }^{10}$ Catorce canciones del disco Rebel Heart fueron filtradas en Internet antes de que fuera terminado y lanzado comercialmente.
} 
"Protección de Datos de Carácter Personal", sin embargo, basta ver la fecha de su promulgación para inferir que la circulación de datos a través de plataformas digitales no era considerada. Si bien en 2014 se plantea la idea de legislar sobre el uso de las redes sociales, ninguna de estas iniciativas particulares tiene mucho sentido, pues la Web no tiene localización geográfica y tendría que promulgarse una suerte de derecho internacional. Cualquier otra opción resulta prácticamente inaplicable en el ciberespacio.

No obstante, el tema es complejo, puesto que, como afirman González Manzano et al. (2014), hay muchas preguntas abiertas, por ejemplo, cómo gestionar que un comentario o imagen de un usuario sea copiado o redistribuido o cómo gestionar el hecho de que un usuario escriba algo sobre otro. Además, antes de eliminar un contenido, es imprescindible contrastar este derecho con otros, por ejemplo, el de la Libertad de Expresión o el de Acceso a la Información Pública (Ley de Transparencia, en Chile).

Por otra parte, Twitter informó que se borrarán las fotografías y vídeos de personas ya fallecidas a petición de la familia. Sin embargo, en este último punto, no se aceptarán todos los casos, debido a que en muchos puede existir contenido informativo o interés público, pero, también desde agosto de 2014 comenzaron a aparecer en la línea de tiempo tuits de personas que no necesariamente son seguidas por el usuario, incluso si no son retuiteados con objeto de ser ayudar a las personas recién llegadas a la plataforma y que no saben a quién seguir, para lo cual Twitter seleccionará los mensajes de acuerdo a la popularidad, el perfil y la interacción de los demás usuarios. Esto implica que los tuits podrán aparecer en la línea de tiempo de otros usuarios, con lo que se pueden recibir respuestas imprevistas de personas que el usuario no conoce ${ }^{11}$.

Para Graux, Ausloos y Valcke (2013), a pesar del interés compartido en la legitimidad de llevar información personal para la atención del público, el debate actualmente en curso en torno a un derecho al olvido (the right to be forgotten) no coincide completamente con los contornos de un droit à l'oubli, del lenguaje legal francés. Fundamentalmente, el droit à l'oubli es una parte de la vida privada derecho fundamental (artículo 7 de la Carta de los Derechos Fundamentales de la Unión Europea). El derecho a ser olvidado (the right to be forgotten), por el contrario, se considera como un aspecto de la protección de datos personales (artículo 8 de la Carta); se refiere fundamentalmente a la creación y mantenimiento de un nivel razonable de privacidad de la información a través de mecanismos de control de los datos personales correspondientes. Esta distinción también se

11 Ver diario La Tercera, 20 de agosto de 2014. http://www.latercera.com/noticia/ tendencias/2014/08/659-592129-9-twitter-eliminara-contenido-de-usuarios-fallecidos-e-incluiramensajes-de.shtml. 
refleja en un enfoque diferente: mientras que el droit à l'oubli ha tendido a ser invocado como un escudo contra la intrusión desproporcionada por los medios tradicionales (periódicos, noticieros, etc.) en la vida privada de las personas que han entrado en la esfera pública, el derecho a ser olvidado no tiene esa tradición o connotación. Una persona que ha publicado imágenes indiscretas o inapropiadas, vídeos o declaraciones en un sitio web público podría sufrir por esto durante mucho tiempo, incluso en ausencia de cualquier enfoque orquestado o dirigido por los principales reproductores multimedia. En efecto, basta con que su nombre esté conectado a dichos materiales a través de motores de búsqueda web y similares para causar significativa vergüenza, estigma o daño.

Korenhof, Ausloos et al. (2014) afirman que los seres humanos siempre han usado memorias externas, pero con la adopción de la tecnología de la información, los mecanismos de "recordar" y "olvidar" en los procesos de la memoria externa parecen haber cambiado drásticamente. El olvido en el cerebro humano surge por la combinación de varios factores. Dicho de manera simple, tres factores principales juegan un rol en la ocurrencia de olvidar con respecto a una pieza específica de información: el paso del tiempo, el significado de la información y la regularidad con la cual la información es usada (nuestra traducción). La praxis de la memoria transformada del almacén de la memoria humana que olvida "by default" ${ }^{12}$ a los almacenes de la memoria externa que generalmente recuerdan "by default" y que requiere activar el olvido por selección para hacer espacio para la información más importante. Pero con el "giro digital", esta necesidad de 'olvidar-por-selección' cambió y disminuyó drásticamente, debido a la continua disminución de los costos de espacio de almacenamiento para la información codificada digitalmente. De hecho, la necesidad de 'olvidar-por-selección' se ha vuelto tan vacía, que a menudo es más barato obtener nuevo o más espacio de almacenamiento que gastar esfuerzo para borrar la información (nuestra traducción).

\section{CONCLUSIÓN}

No cabe duda que la Web es uno de los adelantos tecnológicos más importantes en la historia de la humanidad y que ha abierto un sinfín de posibilidades a los usuarios, al tiempo que las redes sociales permiten que millones de personas se comuniquen entre sí sin costo alguno y de manera inmediata, sin embargo, también tienen un lado oscuro. El incesante tráfico de información a través del ciberespacio posibilita el acceso al conocimiento, a la información respecto de lo que acontece en los más diversos ámbitos y también a saber respecto de los demás.

\footnotetext{
${ }^{12}$ En informática, 'por defecto', es decir, como configuración determinada.
} 
Pero cuando el derecho a la privacidad se diluye entre los millones de bits que circulan en la Red, todo usuario se torna vulnerable y la imposibilidad de decidir qué se hace con los datos personales constituye la más inquietante característica de esta tecnología.

Si bien es cierto que la memoria es parte fundamental de la esencia del hombre y base de la cultura, el olvido es importante para la vida en sociedad. Así como la memoria se cultiva y los recuerdos se preservan, también se ha fijado en el inconsciente colectivo que forgive is forget, que olvidar es perdonar, expresiones que demuestran que en muchos casos el olvido es una recompensa y, a partir de allí, la proclama política "ni perdón ni olvido" confirma lo anterior. Por este motivo, el derecho a ser olvidado se convierte, en la actualidad, en uno de los derechos más importantes, pero a la vez el más esquivo, puesto que hasta el momento no hay conciencia que la publicación de contenidos sin el consentimiento de las personas deben ser considerados como atentado a los derechos humanos. Por este motivo, si bien es cierto que es importante celebrar la memoria, en la actualidad también debiéramos celebrar el olvido.

\section{REFERENCIAS}

De Kerckhove, Derrick. Inteligencias en conexión. Hacia una sociedad de la Web. Barcelona: Gedisa, 1999.

Dery, Mark. "Have We No Sense of Decency, Sir, at Long Last?": On Adult Diapers, Erectile Dysfunction, and Other Joys of Oversharing, essay on the death of shame and the end of privacy", True/Slant, June 7, 2010.

Eco, Umberto. "Discurso alejandrino" [online], 2003. Disponible en: http// elmalpensante.com/index.php?doc=display_contenido $\&$ id $=1224$ [Consultado el 10 de agosto de 2008].

González Manzano, Lorena, González Tablas, Ana, de Fuentes, José M. y Ribagorda, Arturo. "Seguridad en Redes Sociales: Problemas, tendencias y retos futuros", 2014. Disponible en: http<e-archivo.uc3m.es/handle/10016/18169> [Consultado el 20 de septiembre de 2014].

Graux, Hans, Ausloos, Jef y Valcke, Peggy. "The right to be Forgotten in the Internet Era”, ICRI Research Paper 11 (2012). Disponible en: http//papers. ssrn.com/sol3/papers.cfm?abstract_id=2174896 [Consultado el 23 de septiembre de 2014]. 
Korenhof, Paula, Ausloos, Jef, Szekely, Ivan, Ambrose, Meg, Sartor, Giovanni y Leenes, Ronald. "Timing the Right to Be Forgotten. A study into "time" as a factor in deciding about retention or erasure of data", Social Science Research Network, 2014. Disponible en: http//papers.ssrn.com/sol3/papers. cfm?abstract_id=2436436 [Consultado el 04 de agosto de 2014].

Lévy, Pierre. Cibercultura. Barcelona: Anthropos, 2007.

Mayans i Planells, Joan. El ciberespacio, un nuevo espacio público para el desarrollo de la identidad local. 2003. Disponible en: http//www.cibersociedad.net/ archivo/articulo.php?art=158 [Consultado el 07 de agosto de 2010].

Mayer Schönberger, Viktor. Delete: The virtue of forgetting in the digital age. Princeton: Princeton University Press, 2009.

McLuhan, Marshall; Fiore, Quentin. El medio es el masaje. Un inventario de efectos. Barcelona: Paidós, 2009.

Rosen, Jeffrey. “The Right to Be Forgotten”, Stanford Law Review Online 64 (2012): 88-92. Disponible en: http//www.stanfordlawreview.org/sites/default/files/ online/topics/64-SLRO-88.pdf [Consultado el 27 de agosto de 2014].

Salarelli, Alberto. "Diritto all'oblio e archivi online dei quotidiani: alcune considerazioni sulla memoria sociale ai nostri tempi", Italian Journal of Library and Information Science, 5/1, 2014. Disponible en: http//leo.cineca. it/index.php/jlis/article/viewFile/14/8528 [Consultado el 04 agosto 2014].

Scolari, Carlos. Hipermediaciones. Elementos para una Teoría de la Comunicación Interactiva. Barcelona: Gedisa, 2008.

Tich, Steven. "It's Not Personal: the Dangers of Misapplied Privacy Policies to Search, Social Media and Other Web Content”, Policy Study 414 (2013). Los Angeles: Reason Foundation. Disponible en: http//reason.org/files/ online_privacy_policies.pdf [Consultado el 28 septiembre 2014].

Žižek, Slavoj. El sublime objeto de la ideología. México: Siglo XXI Editores, 2008. 